\title{
Identification of factors determining the initiation of breastfeeding in postnatal women in a tertiary care centre: an observational study
}

\author{
Manisha Gupta*, Neelima Agarwal, Alpana Agrawal
}

Department of Obstetrics and Gynecology, Santosh Medical College and Hospitals, Ghaziabad, Uttar Pradesh, India

Received: 15 March 2019

Accepted: 09 April 2019

*Correspondence:

Dr. Manisha Gupta,

E-mail: manishagzyahoo.com

Copyright: (C) the author(s), publisher and licensee Medip Academy. This is an open-access article distributed under the terms of the Creative Commons Attribution Non-Commercial License, which permits unrestricted non-commercial use, distribution, and reproduction in any medium, provided the original work is properly cited.

\begin{abstract}
Background: The WHO recommends that mothers worldwide to initiate breastfeeding within an hour of delivery to achieve optimal growth, development and health but the breastfeeding rates remain far below the recommended standards. The aim of this study was to find the prevalence of delay in initiation of breast feeding, to identify various factors which determine the initiation of breastfeeding and to correlate their association with delayed onset of breast feeding.

Methods: Hundred and thirty six postnatal women, who delivered in Santosh Medical College and Hospital, Ghaziabad, were recruited in the study. They were interviewed after their informed consent using a pretested structured questionnaire. Socio-demographic and obstetric factors were compared between subjects who initiated breast feeding in less than and more than 1 hours. Frequencies were calculated for different variables. Data was statistically analyzed and $\mathrm{p}$ value of $<0.05$ was taken significant.

Results: The prevalence of delay in initiation of breast feeding in our study was found to be $74.2 \%(\mathrm{n}=101)$. The mean time of initiation of breast feeding was 18.43 hours. Significant association $(\mathrm{p}<0.05)$ was found in various sociodemographic, obstetrical and social factors.

Conclusions: Identifying mothers at risk of delayed breastfeeding initiation should be the target for breastfeeding promotion during prenatal, antenatal as well as postnatal period. Public health officials and health care providers should consider interventions to promote and support early initiation of breast feeding.
\end{abstract}

Keywords: Breast feeding, Early initiation of breast feeding, Postnatal, Prelacteal feed

\section{INTRODUCTION}

The World Health Organization (WHO) recommends initiation of breastfeeding within an hour of delivery. ${ }^{1}$ Early initiation is beneficial to the newborn as colostrum boosts the immunological system ,supports growth and development, facilitates bonding between mother and baby, stimulates breast milk production, reduces the incidence of post-partum haemorrhage and establishes successful and longer breastfeeding duration..$^{2-4}$ Delaying initiation of breastfeeding is associated with a high incidence of early neonatal mortality and morbidity. $2,5,6$
According to UNICEF, low to middle income countries (LMICs) are disproportionately affected by suboptimal breastfeeding. ${ }^{7}$ An analysis of DHS (Demographic Health Survey) data from 57 LMICs published in 2018 revealed that only $39 \%$ of children were breastfed within an hour of delivery (range by region of 31-60\%). ${ }^{8}$ An analysis by NFHS 4 (National Family and Health Survey 4, 2015-16) has shown that early initiation of breastfeeding in India is $41.5 \% .^{9}$ Given this negative trend, it is important to explore the factors associated with delay in initiation of breast feeding which can help to strategize ways and methods to encourage early initiation of breast feeding. 
The aim of this study was to find the prevalence of delay in initiation of breast feeding. To identify various factors which determine the initiation of breast feeding. To correlate their association with delayed onset of breast feeding.

\section{METHODS}

The study was an observational study conducted in Ghaziabad, Uttar Pradesh, India. After taking ethical clearance from Ethical committee of the Institution, the study was conducted over a period of 3 months from June 2018 to August 2018. Hundred and thirty six women, who delivered in Santosh Medical College and Hospital, Ghaziabad, were recruited in the study. The subjects were interviewed after their informed consent using a pretested structured questionnaire which consisted of sociodemographic and obstetric factors. Sociodemographic factors included age, parity, and education, and residence, type of family and employment status. Obstetric factors were further divided into antenatal, intranatal and postnatal factors. Antenatal factors included questions regarding antenatal supervision, antenatal counseling, any complications and gestation at delivery. Intranatal factors included mode of delivery, any complications, use, of sedation or anaesthesia postnatal factors included the traditions, prelacteal feeds, and sex of the baby. All factors were studied in relation to time of first breast feeding after birth which was recorded in minutes. They were then grouped in who initiated breast feeding in less or more than one hour after delivery. Exclusion criteria were still births and congenital malformations.

\section{Statistical analysis}

The data was collected and tabulated. Analysis was done using Statistical Package for Social Sciences (SPSS) version 21.0. Frequencies were calculated for different variables. Chi square test, student t-test and MannWhitney $U$ test was done where required and $p$ value of $<0.05$ was taken to be statistically significant.

\section{RESULTS}

Total of 136 subjects were recruited out of which 2 had still births and so were not included in the study. The mean age of the subjects was $25.7 \pm 4.4$ years. The mean time of first breast feeding was 18.43 hours (Figure 1). Breastfeeding was a common practice as $99.2 \%$ breastfed the newborns, but only $24.6 \% \quad(n=33)$ initiated breast feeding early.

Sociodemographic factors of subjects and their frequency distribution are tabulated in Table 1. Age more than 30 years, multiparity, education status of the subject and family members. Rural residence and joint family were factors which were significantly associated with early breast feeding (Table 1).

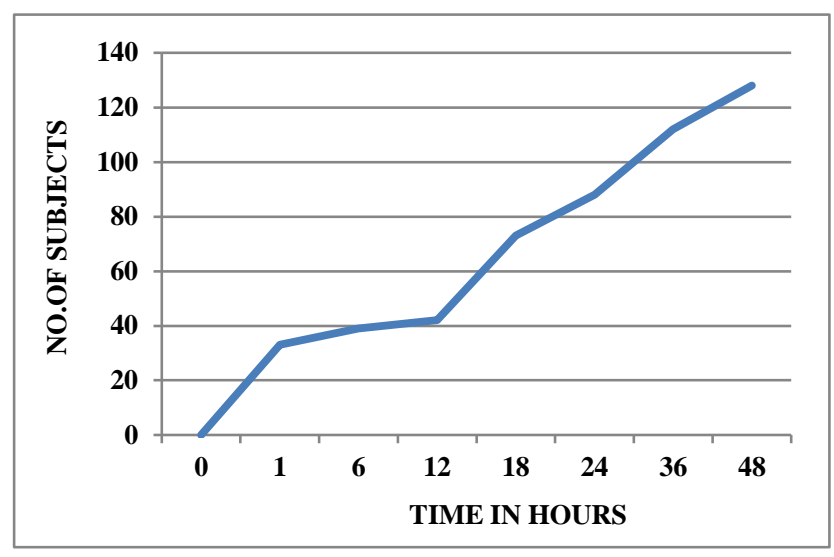

Figure 1: Number of subjects and initiation of breast feeding (hours).

Table 1: Correlation of sociodemographic factors with initiation of breast feeding.

\begin{tabular}{|c|c|c|c|c|c|}
\hline Variable & & $<1$ hour $(\mathrm{n}=33)$ & >1hour $(n=101)$ & p value & OR \\
\hline \multirow{2}{*}{ Age } & $<30$ years & 13 & 51 & \multirow{2}{*}{0.05} & \multirow{2}{*}{2.2} \\
\hline & $>30$ years & 20 & 50 & & \\
\hline \multirow{2}{*}{ Parity } & Primi & 11 & 43 & \multirow{2}{*}{0.05} & \multirow{2}{*}{1.2} \\
\hline & Multi & 22 & 58 & & \\
\hline \multirow{4}{*}{ Education } & Illiterate & 4 & 39 & \multirow{4}{*}{0.008} & \multirow{4}{*}{0.21} \\
\hline & School & 7 & 31 & & \\
\hline & UG & 10 & 19 & & \\
\hline & PG & 12 & 12 & & \\
\hline \multirow{2}{*}{ Education of mother in law } & Educated & 23 & 50 & 0.03 & \multirow{2}{*}{0.2} \\
\hline & Uneducated & 10 & 51 & & \\
\hline \multirow{2}{*}{ Occupation } & Employed & 11 & 13 & \multirow{2}{*}{0.01} & \multirow{2}{*}{3.3} \\
\hline & Unemployed & 22 & 88 & & \\
\hline \multirow{2}{*}{ Family } & Nuclear & 9 & 12 & \multirow{2}{*}{0.03} & \multirow{2}{*}{2.7} \\
\hline & Joint & 24 & 89 & & \\
\hline \multirow{2}{*}{ Residence } & Urban & 13 & 68 & \multirow{2}{*}{0.05} & \multirow{2}{*}{0.4} \\
\hline & Rural & 20 & 33 & & \\
\hline
\end{tabular}


Table 2: Frequency distribution of antenatal factors $(n=134)$.

\begin{tabular}{|c|c|c|c|c|c|}
\hline Variable & & $<1$ hour $(\mathrm{n}=33)$ & $>1$ hour $(n=101)$ & P value & OR \\
\hline \multirow{2}{*}{ Antenatal supervision } & Yes & 24 & 88 & \multirow{2}{*}{0.05} & \multirow{2}{*}{0.4} \\
\hline & No & 9 & 13 & & \\
\hline \multirow{5}{*}{ Counselling } & Doctor & 15 & 10 & \multirow{5}{*}{$<0.0001$} & \multirow{5}{*}{13.5} \\
\hline & Nurse & 7 & 3 & & \\
\hline & Family & 5 & 44 & & \\
\hline & Friends & 3 & 30 & & \\
\hline & Media & 3 & 14 & & \\
\hline \multirow{2}{*}{ Pregnancy complications } & Yes & 4 & 38 & \multirow{2}{*}{0.009} & \multirow{2}{*}{0.22} \\
\hline & No & 29 & 63 & & \\
\hline \multirow{2}{*}{ Gestational age at delay } & $<37$ weeks & 5 & 18 & \multirow{2}{*}{0.72} & \multirow{2}{*}{1.2} \\
\hline & $>37$ weeks & 28 & 83 & & \\
\hline
\end{tabular}

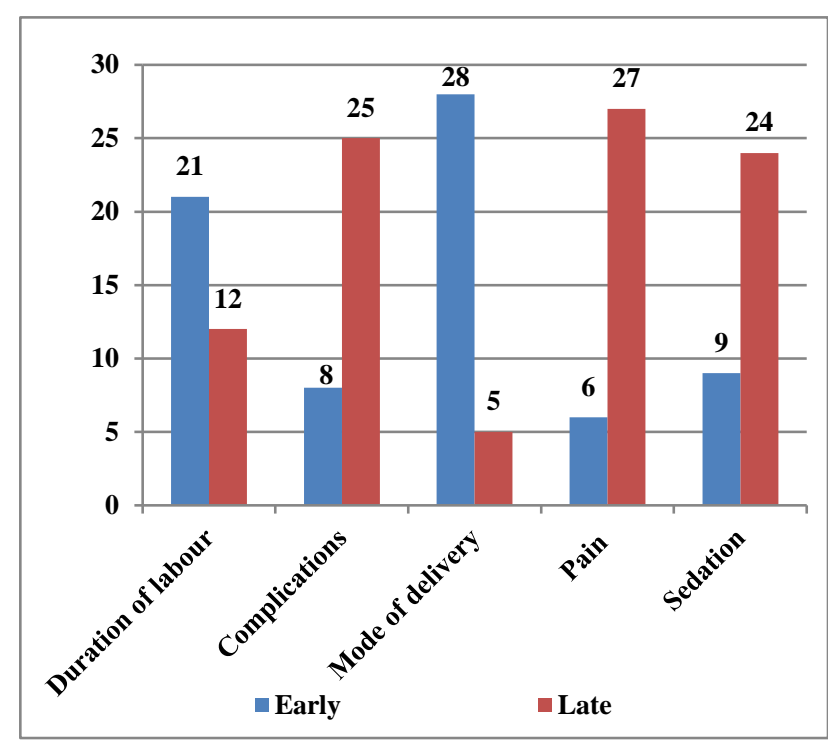

Figure 2: Frequency distribution of intranatal factors.

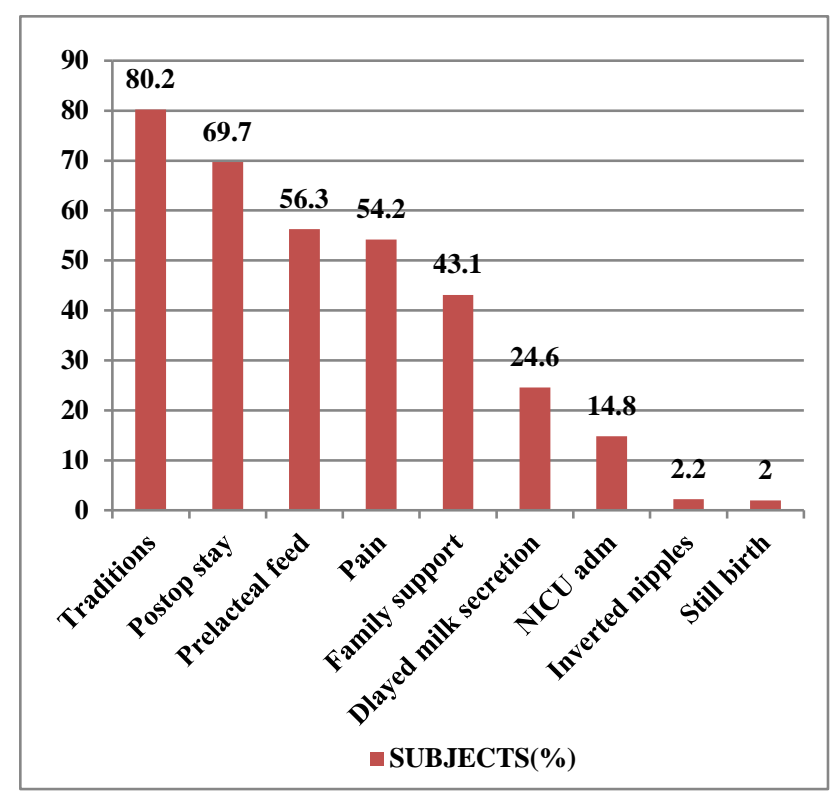

Figure 3: Percentage distribution of postnatal factors.
Out of the 33 women who practiced early initiation, $45.4 \% \quad(n=15)$ and $21.2 \% \quad(n=7)$ of mothers were counselled by doctors and nurses respectively (Figure 2) which depicts the importance of proper antenatal counselling by a trained health personnel.

In the present study labour, more than 12 hours, cesarean delivery, presence of intranatal and postnatal complications, presence of pain and administration of sedation were factors which were significantly associated $(\mathrm{p}<0.05)$ with delayed initiation of breast feeding (Figure 2 and Figure 3 ).

Factors which led to delay in initiation of feeding were post operative stay and pain. Other significant factors were customs of not breast feeding, prelacteal feeds, sex of the baby not coinciding with expectation of mother and NICU admission of the newborn.

\section{DISCUSSION}

Breastfeeding decisions and practices are influenced by multiple factors, including knowledge, attitudes, and beliefs, as well as sociocultural and physiological factors. The aim of this study was to evaluate the prevalence and factors associated with delay in initiation of breastfeeding. The prevalence of delay in initiation of breastfeeding in our study was $74.2 \%$. We found that age more than 30 years, multiparity, education status of both the subject and family members, rural residence, joint family and unemployed status were significantly associated with early initiation of breast feeding.

Despite the recommendations by infant and young child feeding, Government of India and the WHO, delayed initiation of breast feeding was quite high in the study which is comparable to studies in LMICs. ${ }^{11-14}$ The reason for which was found to be that the colostrum was thought to be unworthy of giving to the baby Figure 5. According to a study conducted in western Nepal, a significant number of mothers gave colostrum as the first meal to $86.2 \%$ babies, while the remaining $14 \%$ babies were 
given a fluid other than breast milk as their first feed. ${ }^{15}$ Various family rituals and myths were found to be responsible as in our study. ${ }^{11-14}$ Another reason for the delay was found to be unpopularity of the early skin to skin contact of mother with newborn as recommended by WHO due to separation of the mother-baby pair for routine post-delivery procedures.

Delayed initiation in younger women and primiparous women reflect lack of knowledge and experience on the importance of timely initiation which tends to improve with successive pregnancies. Also concern that their milk may not be enough for baby needs, formula feeds were given to newborn making the newborn vulnerable to various infections.

Urban residence and employed subjects were found to practice delayed initiation. This was in contrast to other studies where rural subjects were more prone to practice delayed breast feeding. ${ }^{13,14}$ This was mainly because of the influence by the marketing tactics used by companies selling "enhanced" infant milk formulas.

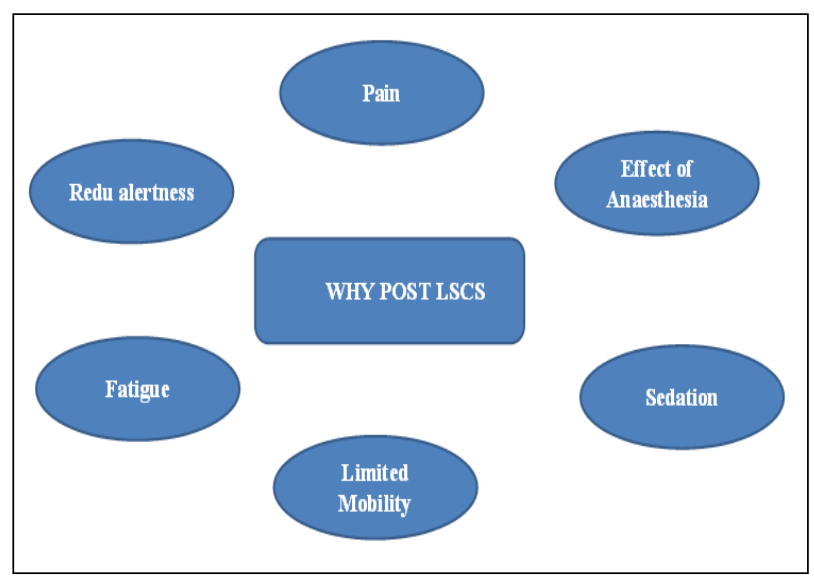

Figure 4: Effects of anaesthesia.

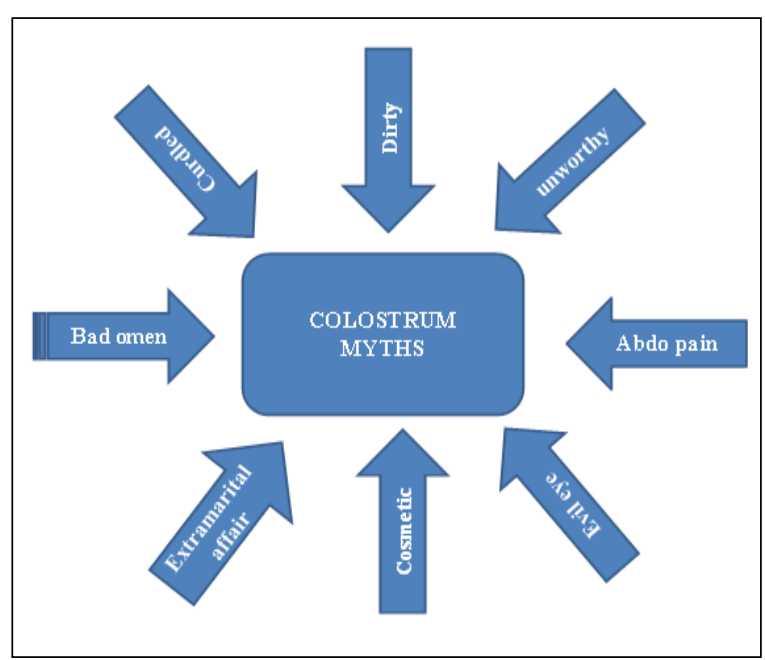

Figure 5: Myths regarding colostrums.
It can be established in the present study that even in institutional deliveries there is gross lack of knowledge regarding the importance of early initiation of breast feeding which is supported in multiple studies. ${ }^{12,13,16}$ Lack of antenatal counseling by a health personnel was found to be significantly associated with delay in initiation of breast feeding in present study.

Similar to other studies, this study also found that subjects with duration of labour more than 12 hours, presence of intranatal and postnatal complications, and a caesarean delivery were also at risk of not initiating breastfeeding early. ${ }^{16}$ Effect of anaesthesia, caesarean procedure, reduced maternal alertness and inadequate maternal skills to initiate breastfeeding are some of the reasons for negative association; with early initiation of breastfeeding (Figure 4). Considering the increasing rates of caesarean delivery globally, it is necessary to encourage and support early initiation of breastfeeding in such women.

Traditions and customs of not feeding with breast, giving prelacteal feeds were the commonest postnatal factors that proved obstacles in early initiation of breast feeding. Apart from the cow milk and honey which were the commonest prelacteal feed given to the newborns, butter, glucose solution and formula milk were also given. This was found in almost all the studies done in LMICs. ${ }^{11-13}$ Various myths and family rituals are of great concern and should be discouraged as they cause lactation failure resulting in high neonatal morbidity and mortality (Figure $5)$.

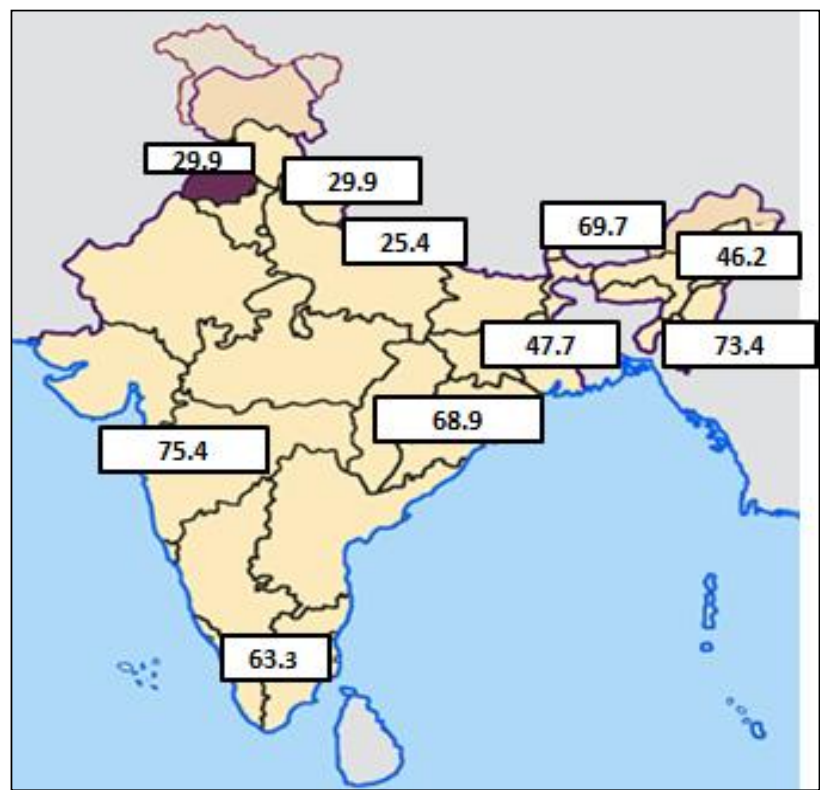

The percentage of children that are breastfed within one hour of birth is very low in Uttar Pradesh $(25 \%)$, the only states in which more than two-thirds of children are breastfed within one hour of birth are Goa, Mizoram, Sikkim, and Odisha.

Figure 6: Early initiation in states of India percentage. 
According to the NFHS 4 (2015-16) percentage of children that are breastfed within one hour of birth is barely $42 \%$, but over $81 \%$ of newborns begin breast feeding within one day. The early initiation is very low in Uttar Pradesh $(25 \%)$, the only states in which more than two-thirds of children are breastfed within one hour of birth are Goa, Mizoram, Sikkim, and Odisha (Figure 6). Twenty-one percent of children received a prelacteal feed which ranged from a minimum of 3 percent of children in Tripura to a maximum of 42 percent of children in Uttar Pradesh (Figure 7). Children whose delivery was assisted by health personnel $(43 \%)$ or who were born at a health facility $(43 \%)$ were more likely to start breastfeeding within one hour of birth than other children. ${ }^{9}$ Thus NFHS 4 supports this finding that education status, family traditions and counseling by a health personnel are three most significant factors which affect the time of initiation of breast feeding.

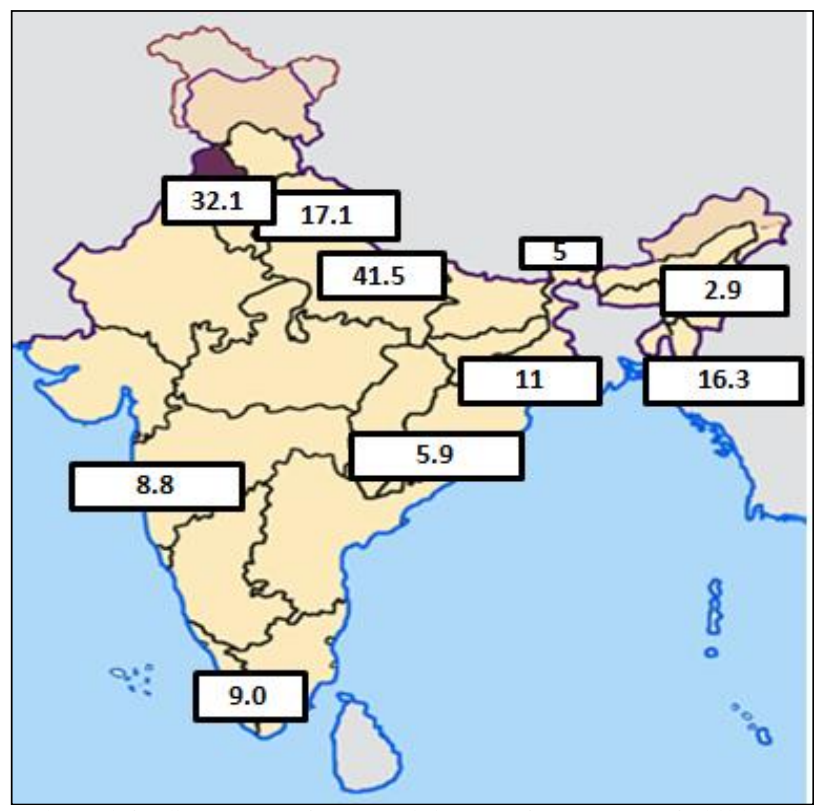

Prelacteal feeding ranges from a minimum of 3 percent of children in Tripura to a maximum of 42 percent of children in UP.

Figure 7: Prelacteal feed percentage in India.

\section{CONCLUSION}

There is a great lacuna in the knowledge, attitude practices and belief of mothers regarding early initiation of breast feeding even in institutional deliveries. Education and antenatal counselling can help in breaking down barriers like family rituals and myths in establishing breast feeding early. Involvement of family is a must and the whole family should be counselled as a unit. Public health officials and health care providers should consider interventions to promote and support early initiation of breast feeding. Last but not the least, various policies made by Health Organisations like WHO UNICEF, etc, may seem very lucrative but how far they are being implemented needs to be thought about and investigated further.

\section{ACKNOWLEDGMENTS}

Authors would like to thank all the women who participated in the study and acknowledge their invaluable contribution in completing the study.

\section{Funding: No funding sources}

Conflict of interest: None declared

Ethical approval: The study was approved by the Institutional Ethics Committee

\section{REFERENCES}

1. World Health Organization (WHO). Protecting, promoting and supporting breastfeeding in facilities providing maternity and newborn services. Geneva: World Health Organization (WHO), 2017. Available at: http://www.who.int/nutrition/ publications/ guidelines/ breastfeeding-facilities-maternitynewborn/en/.

2. Victora CG, Bahl R, Barros AJD, França GVA, Horton S, Krasevec J, et al. Breastfeeding in the $21^{\text {st }}$ century: epidemiology, mechanisms, and lifelong effect. Lancet. 2016;387(10017):475-90.

3. Brandtzaeg P. Mucosal immunity: integration between mother and the breast-fed infant. Vaccine. 2003;21(24):3382-8.

4. Goldman AS. Modulation of the gastrointestinal tract of infants by human milk. Interfaces and interactions. An evolutionary perspective. J Nutr. 2000;130(2S Suppl):426S-31S.

5. Debes AK, Kohli A, Walker N, Edmond K, Mullany LC. Time to initiation of breastfeeding and neonatal mortality and morbidity: a systematic review. BMC Public Health. 2013;13(3):S19.

6. Neovita Study Group. Timing of initiation, patterns of breastfeeding, and infant survival: prospective analysis of pooled data from three randomised trials. Lancet Glob Heal. 2016;4(4):e266-75.

7. United Nations Children's Fund (UNICEF). The state of the world's children 2016: A fair chance for every child. New York; 2016.

8. Oakley L, Benova L, Macleod D, Lynch CA, Campbell OM. Early breastfeeding practices: Descriptive analysis of recent Demographic and Health Surveys. Maternal Child Nutrition. 2018;14(2):e12535.

9. International Institute for Population Sciences (IIPS) and ICF. National Family Health Survey (NFHS-4), 2015-16: India. Mumbai: IIPS; 2017. Available at: http://iipsindia.org.

10. Wen LM, Baur LA, Rissel C, Alperstein G, Simpson JM. Intention to breastfeed and awareness of health recommendations: findings from first-time mothers in southwest Sydney, Australia. Inter Breastfeeding J. 2009;4(1):9.

11. Temesgen H, Negesse A, Woyraw W, Getaneh T, Yigizaw M. Prelacteal feeding and associated factors in Ethiopia: systematic review and meta-analysis. Int Breastfeeding J. 2018;13(1):49. 
12. Mutseyekwa MF, Gunguwo H, Mandigo RG, Mundagowa P. Predictors of early initiation of breastfeeding among Zimbabwean women: secondary analysis of ZDHS 2015. Maternal Heal Neonatol Perinatol. 2019;5(1):2.

13. Ekubay M, Berhe A, Yisma E. Initiation of breastfeeding within one hour of birth among mothers with infants younger than or equal to 6 months of age attending public health institutions in Addis Ababa. Ethiopia newborn services. Int Breastfeed J. 2018;13(1):4.

14. Nguyen PT, Tran HT, Thai TT, Foster K, Roberts CL, Marais BJ. Factors associated with breastfeeding intent among mothers of newborn babies in Da Nang, Viet Nam. Int Breastfeeding J. 2018;13(1):2.

15. Chandrashekhar TS, Joshi HS, Binu V, Shankar PR, Rana MS, Ramachandran U. Breastfeeding initiation and determinants of exclusive breastfeeding: a questionnaire survey in an urban population of western Nepal. Pub Heal Nutr. 2007;5:21.

16. Gavhane S. Knowledge and factors affecting initiation of breast feeding in post-natal mothers in a tertiary care center. Int $\mathrm{J}$ Res Med Sci. 2018;6(2):481-5.

Cite this article as: Gupta M, Agarwal N, Agrawal A. Identification of factors determining the initiation of breastfeeding in postnatal women in a tertiary care centre: an observational study. Int J Reprod Contracept Obstet Gynecol 2019;8:2245-50. 